\title{
Oil mound spreading and migration with ambient groundwater flow in coarse porous media
}

\author{
M. Yavuz Corapcioglu, Kagan Tuncay, ${ }^{1}$ and B. Kagan Ceylan \\ Department of Civil Engineering, Texas A\&M University, College Station
}

\begin{abstract}
When a light, immiscible oil leaks above an unconfined aquifer, it spreads and forms a floating mound on the water table. The oil mound migrates in the direction of ambient groundwater flow. In this study we present a governing equation for the migrating mound thickness by averaging the oil phase mass balance equation. Analytical and numerical solutions to an advective-dispersive type equation are presented to estimate the temporal and spatial distribution of the migrating oil mound thickness for two problems of practical importance: formation, spreading, and migration of an oil mound on the water table and spreading and migration of an established layer of oil with ambient groundwater flow. The model results compare favorably with test data obtained by laboratory flume experiments. Although the model has some simplifying assumptions such as the absence of capillary pressure gradients, sharp saturation changes across the phase interfaces, and single mobile phase (i.e., oil flow only), it can be useful as a screening or site assessment tool because of its relative simplicity.
\end{abstract}

\section{Introduction}

When an immiscible oil lighter than water, e.g., a light nonaqueous phase liquid (LNAPL) such as gasoline, leaks above an unconfined aquifer, it migrates down under the dominant influence of gravity and eventually reaches the water table, where it forms a floating mound of oil on the groundwater surface. The flooding oil can be recovered by two-pump operations [Corapcioglu et al., 1994]. Effective recovery of oil can minimize the remaining contaminant mass in the subsurface. Recovery wells are sited after an investigation using monitoring wells. Observation wells are drilled circumscribing the estimated contaminant extent to determine the thickness of the oil mound on the water table. The accuracy of this technique is directly proportional to the number of wells drilled on the site. One difficult aspect of monitoring subsurface hydrocarbons is that accumulations in monitoring wells do not always directly correspond to the actual or true thickness in the formation [Abdul et al., 1989]. Considering that the hydrocarbon will depress the water within the well at steady state and under capillary equilibrium conditions, the net result is a greater apparent oil thickness measured within the well than actually exists within the aquifer [Abdul et al., 1989; Kemblowski and Chiang, 1990]. The siting of monitoring wells would benefit from a simple model that can be used as a screening tool. Furthermore, such a tool would be useful in assessing how rapidly an oil spill poses a threat to water supply wells in the vicinity.

Migration of nonaqueous phase liquids such as gasoline and fuel oil can be modelled in four general groups: sharp interface models, immiscible phase flow models with capillarity, interphase mass transfer models, and compositional models [Corapcioglu et al., 1993]. As noted by Abriola and Reeves [1990],

\footnotetext{
${ }^{1}$ Now at Izmir Institute of Technology, Izmir, Turkey.

Copyright 1996 by the American Geophysical Union.

Paper number 95WR03825.

0043-1397/96/95WR-03825\$05.00
}

although sharp interface models have some limitations, such as omission of capillary gradients in favor of pressure and gravity gradients, they may be employed for practical purposes because of their relative simplicity. The assumptions of the sharp interface approach are (1) constant soil and fluid properties such as negligible compressibility, constant fluid densities and constant porosity, (2) negligible capillary pressure gradients, (3) sharp saturation changes across the oil-unsaturated soil and oil-groundwater interfaces which allows idealization of saturation-capillary pressure relations as step functions, (4) similar idealization of saturation profiles, (5) single-phase (air in unsaturated soil, water in saturated soil) displacement, (6) assumption of piston-flow displacement, i.e., oil phase only, other phases immobile at residual saturations (as noted by El-Kadi [1994] this assumption is valid for coarse-textured soils where gravity or fluid pressure predominates over capillary forces), and (7) negligible effect of the water table on oil migration and spreading. A review of the literature shows that available studies present sharp interface solutions for oil spreading over a stagnant water table [Corapcioglu et al., 1994]. Although sharp interface models have been investigated by a number of researchers, analytical solutions have been attempted in very few of them. Lateral spreading of oil mounds on water tables has been studied by van Dam [1967], Mull [1971, 1978], Greulich and Kaergaard [1984], Greulich [1985], Holzer [1976], Levy et al. [1990], Schiegg [1977, 1979] and Hochmuch and Sunada [1985]. Van Dam [1967] obtained an expression to estimate the areal extent of an oil mound at equilibrium by assuming a constant oil saturation within the mound and a stationary water table. Mull $[1971,1978]$ presented an analysis by assuming the oil lens to cease spreading when the thickness at the spill site matches the capillary rise. Greulich [1985] (also presented by Greulich and Kaergaard [1984]) represented the oil mound as a combination of a cylinder at the center and a thin circular disc outside. Holzer [1976] applied Hantush's [1968] theory by making an analogy between the decay of an oil mound on a horizontal water table and the movement of a freshwater mound in an unconfined saline aquifer. Levy et al. 
[1990], too, used Hantush's [1967] methodology to estimate the rate and volume of oil leakage from a tank. Hochmuch and Sunada [1985] developed a two-dimensional numerical finiteelement model to simulate the movement of a hydrocarbon and groundwater by solving the Boussinesq equation stated for each phase. Schiegg [1977] (also presented by Schiegg and Schwille [1991]) presented a numerical lateral spreading solution by using a semianalytical vertical infiltration expression as an initial condition. Schiegg assumes that spreading starts after the infiltration of oil ceases. El-Kadi [1994] employed the sharp interface approach to model initial accumulation and spreading of an oil phase on water table. He developed a timedistance profile from Darcy's law by assuming a piston flow of oil. Huyakorn et al. [1994] presented a numerical model to analyze the behavior of nonaqueous phase liquids in groundwater systems by incorporating the gravity-segregated vertical equilibrium concept. The model has been used to simulate crude-oil mound movement at a spill site near Bemidji, Minnesota. Reasonable agreement has been obtained between the sharp interface model predictions and the observed data. A comparative review of these studies has shown that there is a wide range of variation between the expressions obtained by various researchers [Ahmed, 1994; Corapcioglu et al., 1996]. No study takes into consideration the oil mound migration with ambient groundwater flow, i.e., on a sloped water table. In other words, all two-dimensional studies available consider formation and spreading of oil phase on a stagnant water table. Obviously, this is not a realistic assumption. One reason for the lack of an analytical solution for oil mound migration with ambient groundwater flow is the lack of a governing equation simulating spreading and migration processes simultaneously. Furthermore, none of the analytical expressions were validated by comparison to experimental results.

In the last 2 decades, various experimental studies of oil infiltration and spreading have been reported in the literature. Among them, Schiegg [1979], Schwille [1981, 1984], and Schiegg and Schwille [1991] conducted one- and two-dimensional oil infiltration experiments to develop an understanding of nonaqueous phase behavior in porous media. Hochmuth and Sunada [1985] performed two-dimensional experiments in a Plexiglas flume with $2.5-\mathrm{mm}$ glass beads to test a numerical model that assumed zero capillarity. Host-Madsen and Jensen [1992] conducted two-dimensional infiltration experiments and compared the results to their numerical model. Kessler and Rubin [1987], Reible et al. [1990], and Weaver et al. [1994] performed one-dimensional experiments to validate their modeling studies of oil filtration.

In this study we present a model to estimate spreading and migration of an oil mound with ambient groundwater flow. The analysis is designed for application to LNAPL spills and leaks. The analytical solutions are obtained by applying the Fourier transformation to vertically averaged linear partial differential equations governing the oil flow in porous media. Experimental data obtained under controlled laboratory conditions are used to compare and test the validity of the model. Experimental oil migration studies are conducted in a large-scale laboratory flume filled with a silica sand. Soltrol-130, a commercial immiscible fluid, is used as the oil phase. Studies are conducted to provide a methodology for two important oil spill problems: formation, spreading, and migration of an oil mound on the water table and migration of an established oil mound with ambient groundwater flow. The latter is generally known as the "pancake" problem in practice.

\section{Derivation of Governing Equation}

To develop a governing equation in terms of oil thickness to simulate oil mound spreading and migration with ambient groundwater flow, our starting point is the mass balance equation of the oil phase in a porous medium

$$
\nabla \cdot \rho_{\mathrm{o}} \mathbf{q}_{\mathrm{o}}+\frac{\partial\left(\rho_{\mathrm{o}} S_{\mathrm{o}} n\right)}{\partial t}=0
$$

where $\rho_{o}$ is the density of the oil phase; $q_{o}$ is the specific discharge of the oil phase; $S_{\mathrm{o}}$ and $S_{\mathrm{w}}$ are the degrees of phase saturations of oil and water phases, respectively; $t$ is the time, and $n$ is the porosity. Note that in a two-phase system, $S_{0}+$ $S_{\mathrm{w}}=1$. In this study we will assume that the medium is homogeneous, isotropic, and incompressible. We will also assume that the oil is mobile within the oil mound and that water is immobile at residual saturations.

The objective of our study is to obtain a field equation in terms of oil mound thickness as a function of time and of the plane coordinates only. Then we start by integrating (1), describing oil flow in a three-dimensional space, along the vertical thickness of an oil mound, taking into account the boundary conditions on the top and bottom surfaces, i.e., oil surface and water table. This will yield an equation in terms of oil mound thickness and other parameters which are averaged values. Then specific discharge of oil, $\mathbf{q}_{o}$, can be expressed by Darcy's law in terms of oil potential, $\phi_{0}$,

$$
\mathrm{q}_{\mathrm{o}}=-K_{\mathrm{o}} \nabla \phi_{\mathrm{o}}=-K_{\mathrm{o}} \nabla\left(h-\frac{P_{\mathrm{ao}}}{\rho_{\mathrm{o}} g}\right) \approx-K_{\mathrm{o}} \nabla h
$$

where $K_{\mathrm{o}}$ is the hydraulic conductivity of oil, $\phi_{\mathrm{o}}$ is the potential head of oil, $p_{\text {ao }}$ is the capillary pressure between air and oil phases, $g$ is the gravitational acceleration, and $h$ is the elevation of the mound surface. In (2) we neglect the capillary pressure gradient in accordance with the sharp interface assumptions.

Averaging (1) along the vertical in the oil from $\eta(r, t)$ to $h(r, t)$ and expressing the mound thickness as $L(x, y, t)=$ $h(x, y, t)-\eta(x, y)$ under steady state groundwater flow conditions (i.e., $\partial \eta / \partial t=0$ ), substituting (2), and rearranging yields [Corapcioglu et al., 1994; Lingam and Corapcioglu, 1995]

$$
\begin{gathered}
\nabla \cdot\left(\rho_{\mathrm{o}} K_{\mathrm{o}} L \nabla L\right)+\nabla \cdot\left(\rho_{\mathrm{o}} K_{\mathrm{o}} L \nabla \eta\right)= \pm \rho_{\mathrm{o}} Q_{\mathrm{o}} \delta(x-\xi) \delta(y-\zeta) \\
+n \rho_{\mathrm{o}}\left(S_{\mathrm{oo}}-S_{\mathrm{oun}}\right)(\partial L / \partial t)
\end{gathered}
$$

where $S_{\text {oo }}$ and $S_{\text {oun }}$ are degrees of oil saturation in the oil mound and in the unsaturated soil, respectively, and $\eta$ is the elevation of the water table. $Q_{\mathrm{o}}$ is the rate of oil leak/pumpage at the point $(\xi, \zeta)$. A minus sign on the right-hand side denotes an oil leak; $\delta$ denotes the Dirac delta function. The details of vertical averaging of (1) are given by Corapcioglu et al. [1994]. As seen in (3), the residual saturations of oil is incorporated in the formulation in the storage term.

When an oil layer of finite extent rests on the water table which is the oil-water interface, under hydrostatic conditions, we can state the following expressions for the oil and water pressures, $P_{\mathrm{o}}$ and $P_{\mathrm{w}}$, respectively, in terms of oil and water potential heads, $\phi_{\mathrm{o}}$ and $\phi_{\mathrm{w}}$, respectively

$$
P_{\mathrm{o}}=\rho_{\mathrm{o}} g\left(\phi_{\mathrm{o}}-\eta\right) \quad P_{\mathrm{w}}=\rho_{\mathrm{w}} g\left(\phi_{\mathrm{w}}-\eta\right)
$$

where $\eta$ is the elevation of the water table as measured from a datum and $\rho_{\mathrm{o}}$ and $\rho_{\mathrm{w}}$ are the densities of oil and water, respec- 
tively. Neglecting the capillary pressure between the oil and water phases, i.e., $P_{\mathrm{o}}=P_{\mathrm{w}}$, the potential head of water is obtained from (4) as

$$
\phi_{\mathrm{w}}=\left(1-\frac{\rho_{\mathrm{o}}}{\rho_{\mathrm{w}}}\right) \eta+\frac{\rho_{\mathrm{o}}}{\rho_{\mathrm{w}}} \phi_{\mathrm{o}}
$$

Noting that the elevation of the air-oil interface, $h$ (i.e., oil surface), as measured from the datum is the sum of the oil mound thickness $L$ and $\eta$ (i.e., $h=\eta+L$ ) and that by neglecting the capillary pressure between the oil and air phases (i.e., $\phi_{\mathrm{o}}=h$ ) the specific discharge of water $\mathbf{q}_{\mathrm{w}}$ can be expressed by Darcy's law as

$$
\mathbf{q}_{\mathrm{w}}=-K_{\mathrm{w}} \nabla \phi_{\mathrm{w}}=-K_{\mathrm{w}} \nabla \eta-K_{\mathrm{w}} \frac{\rho_{\mathrm{o}}}{\rho_{\mathrm{w}}} \nabla L
$$

where $K_{\mathrm{w}}$ is the hydraulic conductivity of water. The last term in the right-hand side of (6) accounts for water flow caused by a change in oil thickness. At the maximum oil mound thickness it will not contribute additional water flow. Assuming that the density $\rho_{\mathrm{o}}$ and hydraulic conductivity $K_{\mathrm{o}}$ of oil are constants in accordance with sharp interface assumptions, (3) can be rewritten as

$$
\begin{gathered}
\nabla \cdot(L \nabla L)+\nabla \cdot(L \nabla \eta)= \pm \frac{1}{K_{\mathrm{o}}} Q_{\mathrm{o}} \delta(x-\xi) \delta(y-\zeta) \\
+\left[\frac{n S_{\mathrm{oo}}-n S_{\mathrm{oun}}}{K_{\mathrm{o}}}\right] \frac{\partial L}{\partial t}
\end{gathered}
$$

where $S_{\text {oo }}$ and $S_{\text {oun }}$ are degrees of oil saturation in the oil mound and in the unsaturated soil, respectively. Combination and rearrangement of (6) and (7) and the assumption of constant groundwater flow velocity yield

$$
\begin{gathered}
\left(1-\frac{\rho_{\mathrm{o}}}{\rho_{\mathrm{w}}}\right) \nabla \cdot(L \nabla L)-\frac{\mathbf{q}_{\mathrm{w}}}{K_{\mathrm{w}}} \nabla L= \pm \frac{1}{K_{\mathrm{o}}} Q_{\mathrm{o}} \delta(x-\xi) \delta(y-\zeta) \\
+\left[\frac{n S_{\mathrm{oo}}-n S_{\mathrm{oun}}}{K_{\mathrm{o}}}\right] \frac{\partial L}{\partial t}
\end{gathered}
$$

In (8) the second-order terms such as $\nabla L \cdot \nabla L$ can be neglected for small values of $\nabla L$. The omission of second-order terms in groundwater flow equations is a common practice [e.g., Verruijt, 1969; Bear, 1972]. However, this might be a limitation in some cases due to the large gradients at very early times. Then (8) can be rewritten by linearizing the resulting equation as

$$
\begin{array}{r}
\frac{K_{\mathrm{o}} L_{\mathrm{o}}\left(\rho_{\mathrm{w}}-\rho_{\mathrm{o}}\right)}{n \rho_{\mathrm{w}}\left(S_{\mathrm{oo}}-S_{\mathrm{oun}}\right)} \nabla^{2} L-\frac{\mathrm{q}_{\mathrm{w}} K_{\mathrm{o}}}{K_{\mathrm{w}} n\left(S_{\mathrm{oo}}-S_{\mathrm{oun}}\right)} \nabla L \\
\quad=\frac{\partial L}{\partial t} \pm \frac{Q_{\mathrm{o}}}{n\left(S_{\mathrm{oo}}-S_{\mathrm{oun}}\right)} \delta(x-\xi) \delta(y-\zeta)
\end{array}
$$

where $L_{\mathrm{o}}$ is a reference thickness of the oil mound. There are several techniques to linearize nonlinear partial differential equations. Bear [1972] outlined three of these techniques. We used the simplest and most widely used technique, in which an averaged thickness of the oil, $L_{\mathrm{o}}$, is introduced. Kemblowski and Chiang [1990] suggested $L_{\mathrm{o}}$ as the volume of oil per unit area of the aquifer divided by the porosity. Equation (9) is an advective-dispersive transport equation. The advective term, which is proportional to specific discharge of water, represents the migration of oil mound with ambient groundwater flow.

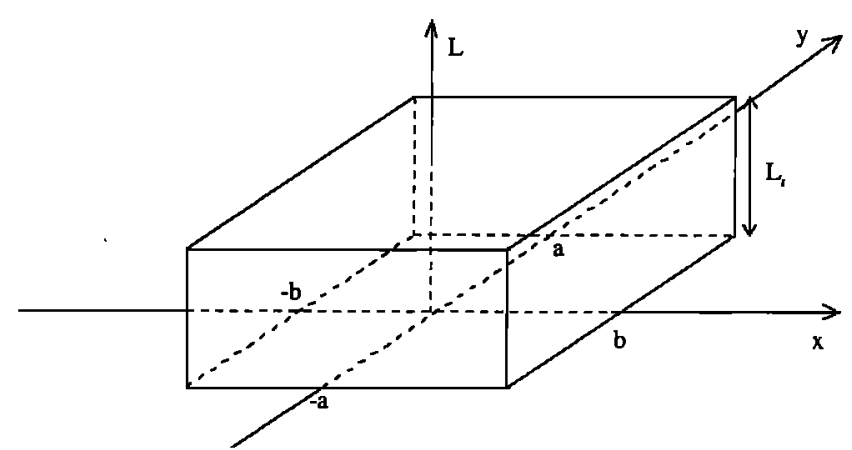

Figure 1. Schematic of the oil mound geometry on the water table.

The dispersion term represents the gravitational spreading of oil mound on the water table due to its density difference $\left(\rho_{w}-\rho_{\mathrm{o}}\right)$. The center of the oil mass would move at a velocity established by the slope of the water table $\left(\mathbf{q}_{\mathrm{w}} / K_{\mathrm{w}}\right)$ times the oil hydraulic conductivity $K_{\mathrm{o}}$ divided by the oil-filled pore space $\left[n\left(S_{\text {oo }}-S_{\text {oun }}\right)\right]$.

\section{Solution Techniques}

Solutions of (9) will be presented for two practical problems: formation and spreading of an oil mound on the water table and spreading and migration of an established oil mound with ambient groundwater flow. We will take the direction of ambient flow as the $x$ direction and the origin $x=0, y=0$, as the location of the oil leak. Then rearrangement of (9) yields the following form in Cartesian coordinates

$$
\frac{\partial^{2} L}{\partial x^{2}}+\frac{\partial^{2} L}{\partial y^{2}}-V \frac{\partial L}{\partial x}=R \frac{\partial L}{\partial t}-C \delta(x) \delta(y)
$$

where

$$
\begin{gathered}
V=\frac{\mathbf{q}_{\mathrm{w}}}{K_{\mathrm{w}} L_{\mathrm{o}}\left(1-\rho_{\mathrm{o}} / \rho_{\mathrm{w}}\right)} \quad R=\frac{n\left(S_{\mathrm{oo}}-S_{\mathrm{oun}}\right)}{K_{\mathrm{o}} L_{\mathrm{o}}\left(1-\rho_{\mathrm{o}} / \rho_{\mathrm{w}}\right)} \\
C=\frac{Q_{\mathrm{o}}}{K_{\mathrm{o}} L_{\mathrm{o}}\left(1-\rho_{\mathrm{o}} / \rho_{\mathrm{w}}\right)}
\end{gathered}
$$

Application of the Fourier transform to (10) in $x$ and $y$ directions yields

$$
-\lambda_{x}^{2} \bar{L}-\lambda_{y}^{2} \bar{L}-i \lambda_{x} V \bar{L}=R \frac{d \bar{L}}{d t}-C
$$

where $\bar{L}\left(\lambda_{x}, \lambda_{y}, t\right)$, the transform of $L$, is defined as

$$
\bar{L}\left(\lambda_{x}, \lambda_{y}, t\right)=\int_{-\infty}^{+\infty} \int_{-\infty}^{+\infty} L(x, y, t) e^{i \lambda_{x} x} e^{i \lambda_{y} y} d x d y
$$

where $\lambda_{x}$ and $\lambda_{y}$ are the transform parameters in the $x$ and $y$ directions, respectively. Equation (12) is a first-order ordinary differential equation whose independent variable is time $t$. The solution of (12) is

$$
\begin{gathered}
\bar{L}\left(\lambda_{x}, \lambda_{y}, t\right)=A \exp \left(-\frac{\lambda_{x}^{2}+\lambda_{y}^{2}+i \lambda_{x} V}{R} t\right) \\
+\frac{C}{\lambda_{x}^{2}+\lambda_{y}^{2}+i \lambda_{x} V}
\end{gathered}
$$



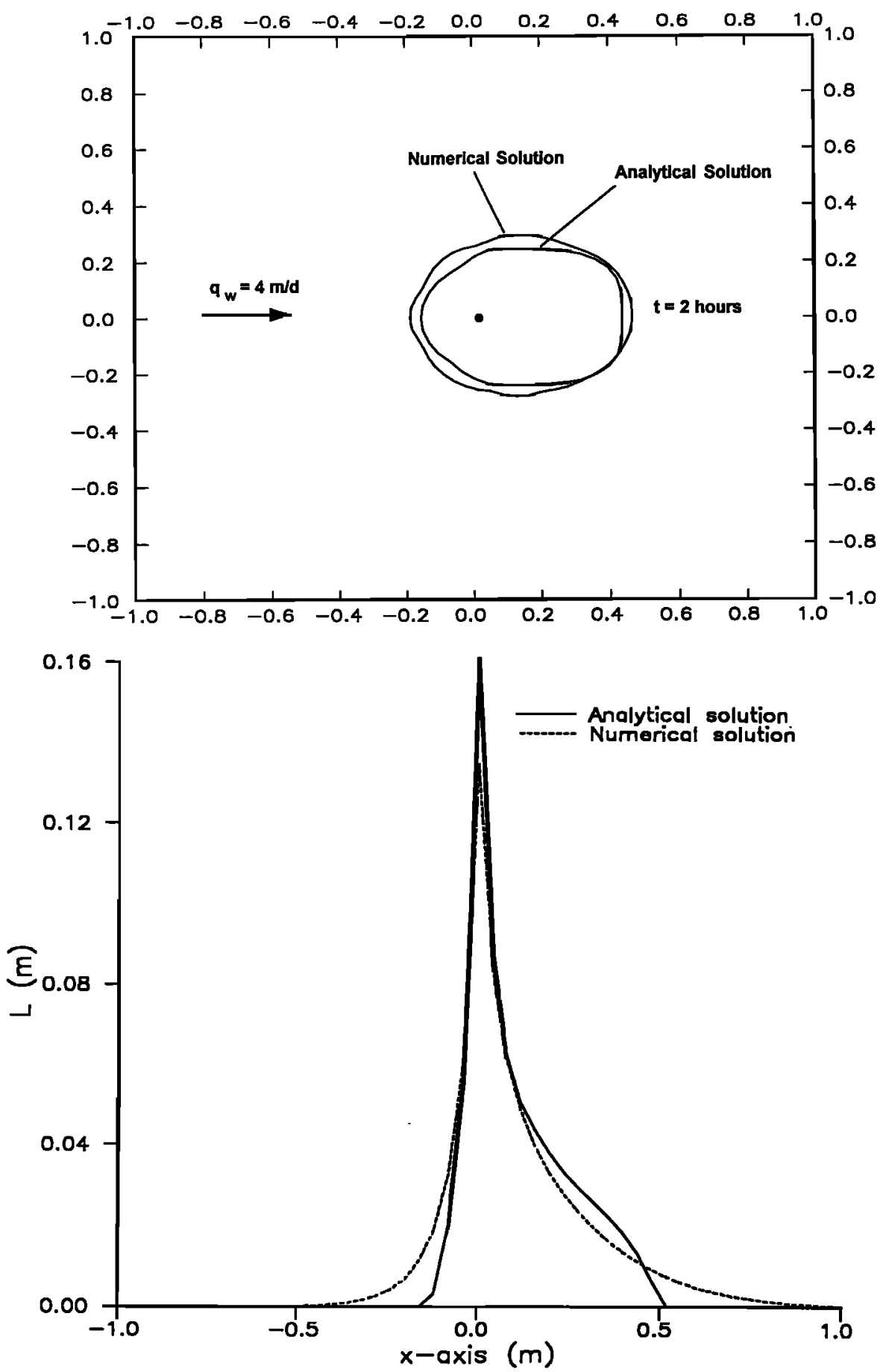

Figure 2. Oil mound spreading and migration at $t=2$ hours: Comparison of analytical (equation (18)) and numerical solutions of $L=1 \mathrm{~cm}$ contours and oil mound profiles along $y=0$.

where $i$ is the imaginary number and $A$ is an integration constant obtained from the initial condition of the problem. When the oil extends initially from $x=-b$ to $x=b$ and from $y=$ $-a$ to $y=a$ with a uniform thickness $L_{i}$ (see Figure 1), the Fourier transform of the initial condition is given by

$$
\bar{L}\left(\lambda_{x}, \lambda_{y}, 0\right)=\frac{4 L_{1}}{\lambda_{x} \lambda_{y}} \sin \left(\lambda_{x} b\right) \sin \left(\lambda_{y} a\right)
$$

The integration constant $A$ of (14) is obtained as

$$
A=\bar{L}\left(\lambda_{x}, \lambda_{y}, 0\right)-\frac{C}{\lambda_{x}^{2}+\lambda_{y}^{2}+i \lambda_{x} V}
$$

The inverse of the Fourier transform is defined as

$$
L(x, y, t)=\frac{1}{4 \pi^{2}} \int_{-\infty}^{+\infty} \int_{-\infty}^{+\infty} \bar{L}\left(\lambda_{x}, \lambda_{y}, t\right) e^{-i \lambda_{x} x} e^{-\imath \lambda_{y} y} d \lambda_{x} d \lambda_{y}
$$



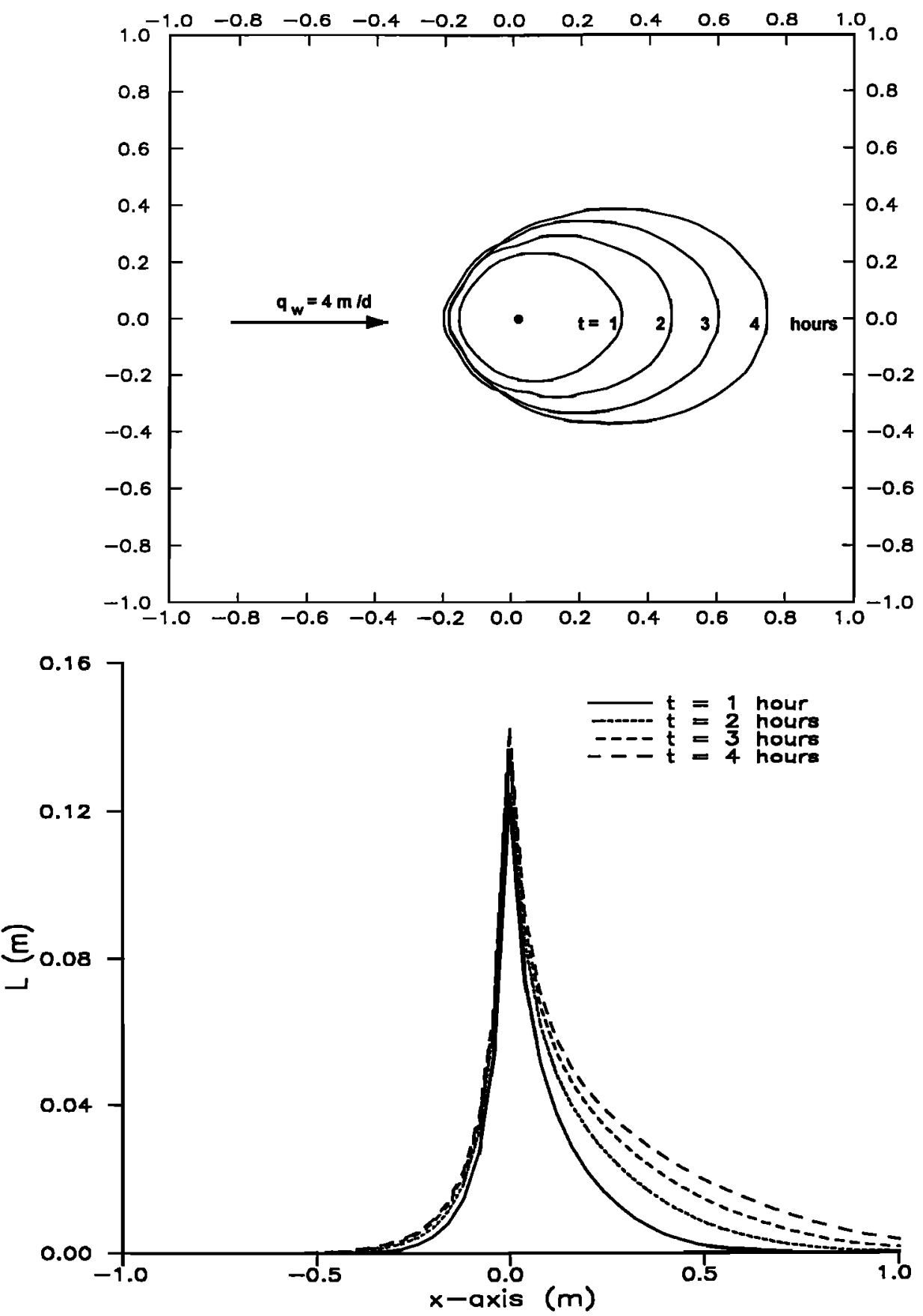

Figure 3. Oil spreading and migration resulting from a leak located at $x=0, y=0: L=1 \mathrm{~cm}$ contours and oil mound profiles along $y=0$.

The integrand in (17) has imaginary and real parts. Since the oil thickness $L$ must have a real value, the solution is obtained for the real values of $L$ as the following after some algebraic manipulations

$$
\begin{gathered}
L(x, y, t)=\frac{1}{4 \pi^{2}} \int_{-\infty}^{+\infty} \int_{-\infty}^{+\infty}\left[\left(B_{6}-\frac{B_{2}}{B_{1}}\right) \cos \left(B_{5}+B_{7}\right) e^{-B_{4} t}\right. \\
-\frac{B_{3}}{B_{1}} \sin \left(B_{5}+B_{7}\right) e^{-B_{4} t}+\frac{B_{2}}{B_{1}} \cos \left(B_{7}+B_{8}\right) \\
\left.+\frac{B_{3}}{B_{1}} \sin \left(B_{7}+B_{8}\right)\right] d \lambda_{x} d \lambda_{y}
\end{gathered}
$$

where

$$
\begin{gathered}
B_{1}=\left(\lambda_{x}^{2}+\lambda_{y}^{2}\right)^{2}+\lambda_{x}^{2} V^{2} \quad B_{2}=C\left(\lambda_{x}^{2}+\lambda_{y}^{2}\right) \quad B_{3}=C \lambda_{x} V \\
B_{4}=\left(\lambda_{x}^{2}+\lambda_{y}^{2}\right) / R \quad B_{5}=\lambda_{x}(x-V t / R) \\
B_{6}=\bar{L}\left(\lambda_{x}, \lambda_{x}, 0\right) \quad B_{7}=\lambda_{y} y \quad B_{8}=\lambda_{x} x
\end{gathered}
$$

An inspection of the integrand in (18) shows that the integrand vanishes as $\left|\lambda_{x}\right|$ and $\left|\lambda_{y}\right|$ increase. Because of the harmonic behavior of the integrand, the numerical integration of (18) should be performed with close attention to the limits of $\left|\lambda_{x}\right|$ and $\left|\lambda_{y}\right|$ and the behavior of the integrand as $\lambda_{x} \rightarrow 0$ and 

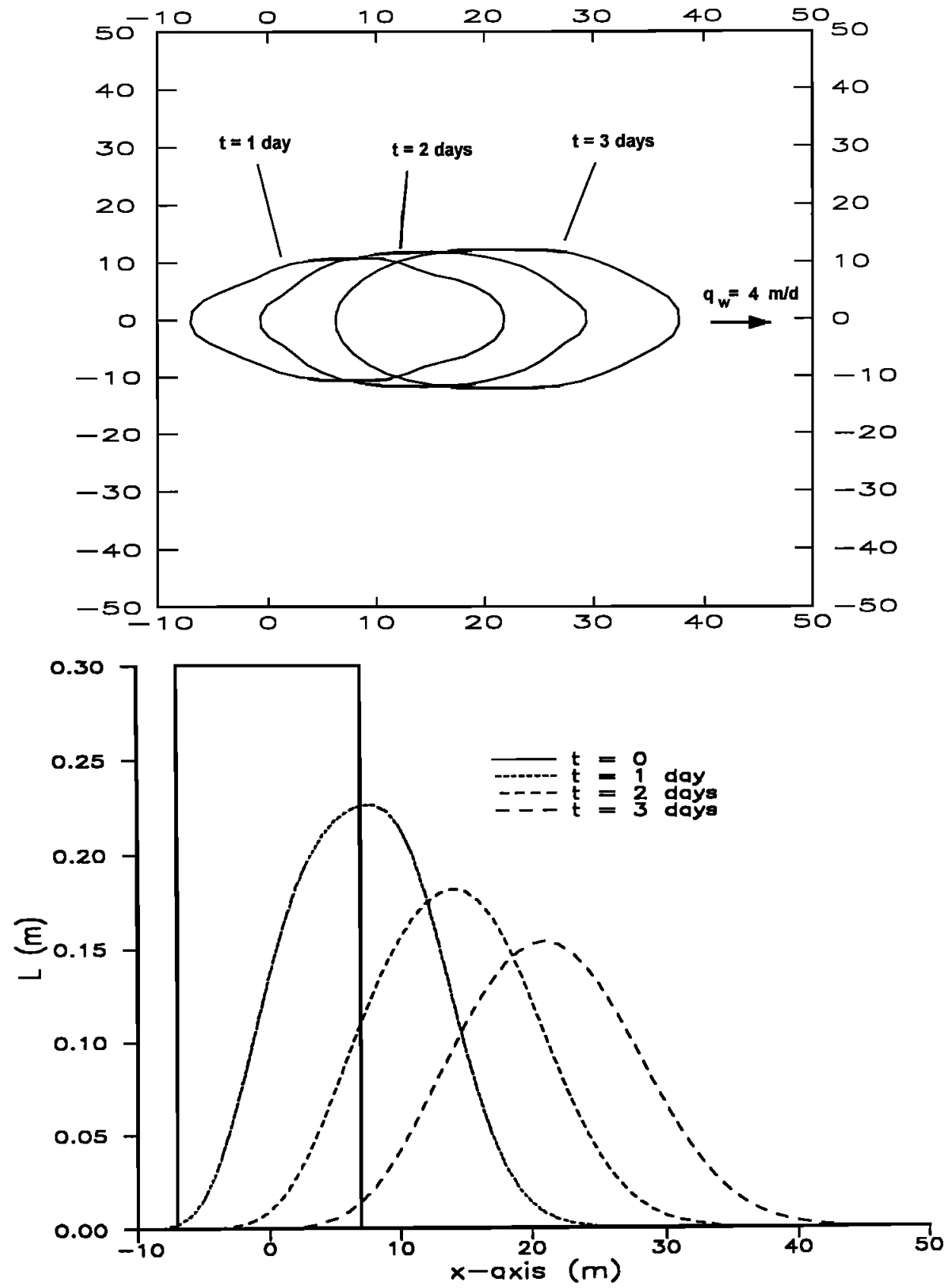

Figure 4. Spreading and migration of an initially rectangular $(14 \mathrm{~m} \times 6 \mathrm{~m})$ oil mound: $L=1 \mathrm{~cm}$ contours and oil mound profiles along $y=0$.

$\lambda_{y} \rightarrow 0$. We also should note that the averaged oil thickness $L_{\mathrm{o}}$ is a function of time. As the oil mound migrates, the averaged mound thickness changes. This might be very crucial in oil leak problems in which the averaged oil mound thickness is not defined at $t=0$. The procedure to calculate $L_{\mathrm{o}}$ at a particular time can be briefly explained as follows. First we calculate the actual volume of oil leaked. In case of an established oil mound, the volume of oil is constant in time. For oil leak problems with a source, the actual volume of oil is the product of time and the leakage rate $Q_{\mathrm{o}}$. Then, we assume a value for $L_{\mathrm{o}}$ (for example, $0.02 \mathrm{~m}$ ) and calculate the oil mound profile by using (18). The volume of oil is computed by integrating the mound profile. Since the calculated volume of oil should be equal to the actual volume, we adjust $L_{\mathrm{o}}$ and continue the routine until the calculated and actual volumes are in a reasonable agreement. This procedure is laborious but appears to be the only rigorous way to find $L_{\mathrm{o}}$.

Because of the difficulties to evaluate the integral in (18), (9) is also solved by using a finite-difference technique. We use the classical implicit scheme with central-difference approximation for spatial derivatives. The resulting set of algebraic equations is solved by iteration. However, any software solving the advective-dispersive transport equation can be used to solve (9) numerically. Furthermore, numerical solution enables us to update $L_{\mathrm{o}}$ without much difficulty as time progresses. We calculate $L_{\mathrm{o}}$ at every time step using the definition "volume of oil per unit area of the aquifer divided by the porosity" and employ it at the next time step. 

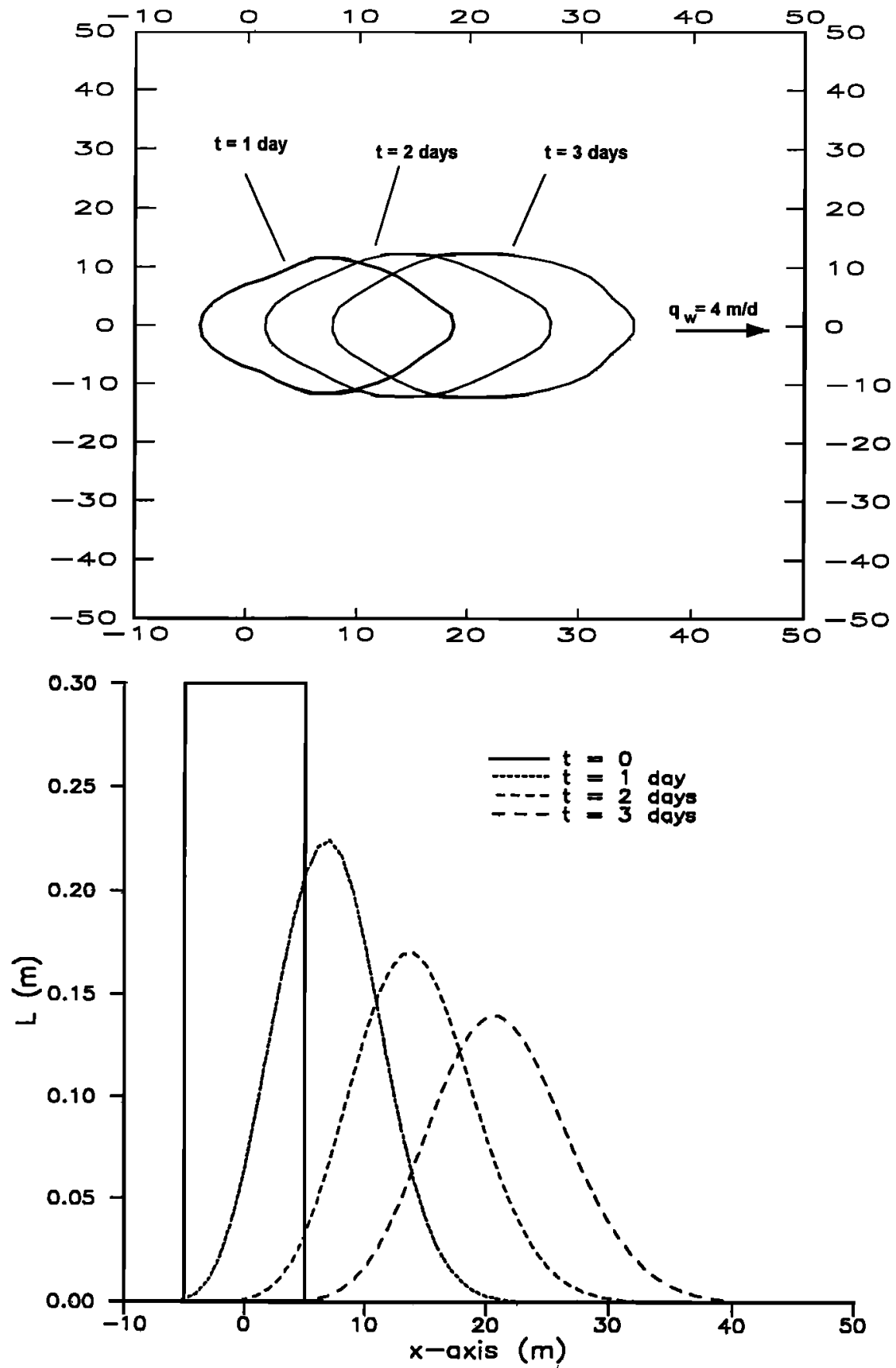

Figure 5. Spreading and migration of an initially circular oil mound with a radius of $5 \mathrm{~m}: L=1 \mathrm{~cm}$ contours and oil mound profiles along $y=0$.

\section{Example Simulations}

Comparisons of analytical and numerical solutions are illustrated in Figure 2 for an oil leak problem with a source located at $x=0, y=0$. The oil leak rate $Q_{0}$ and ambient Darcy

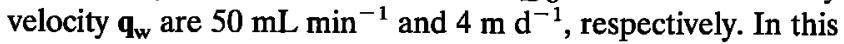
simulation the material parameters are taken as $S_{\mathrm{oo}}=0.9$, $S_{\text {oun }}=0.1, n=0.39, \rho_{\mathrm{w}}=1.0 \mathrm{~g} \mathrm{~cm}^{-3}, \rho_{\mathrm{o}}=0.753 \mathrm{~g} \mathrm{~cm}^{-3}$, $K_{\mathrm{w}}=0.0008 \mathrm{~m} \mathrm{~s}^{-1}$, and $K_{\mathrm{o}}=0.00044 \mathrm{~m} \mathrm{~s}^{-1}$. In the calculations the limits of the integral in (18) are taken as 100. A grid of $100 \times 100$ is used to approximate the integral in (18). In the numerical solution the time step is taken as $100 \mathrm{~s}$. The comparison of analytical and numerical solutions for the oil mound thickness contours of $1 \mathrm{~cm}$ and profiles along $y=0$ at $t=2$ hours show a favorable match. Since $L_{\mathrm{o}}$ is not defined at $t=0$ for an oil leak problem with no initially established oil formation, we start with $L_{\mathrm{o}}=0.1 \mathrm{~m}$ in our numerical solution. Eventually, $L_{\text {o }}$ converges to $0.02 \mathrm{~m}$. Figure 3 illustrates the formation and spreading of the oil mound with time for the same problem. After 4 hours of leakage, the oil mound thickness of $1 \mathrm{~cm}$ extends to $0.7 \mathrm{~m}$ from the source in the direction of ambient groundwater flow. At this time, the maximum oil mound thickness is $14 \mathrm{~cm}$ under the source.

Next we analyze the spreading of an initially rectangular oil established on the water table. The extent of the spill is $14 \mathrm{~m} \times$ 

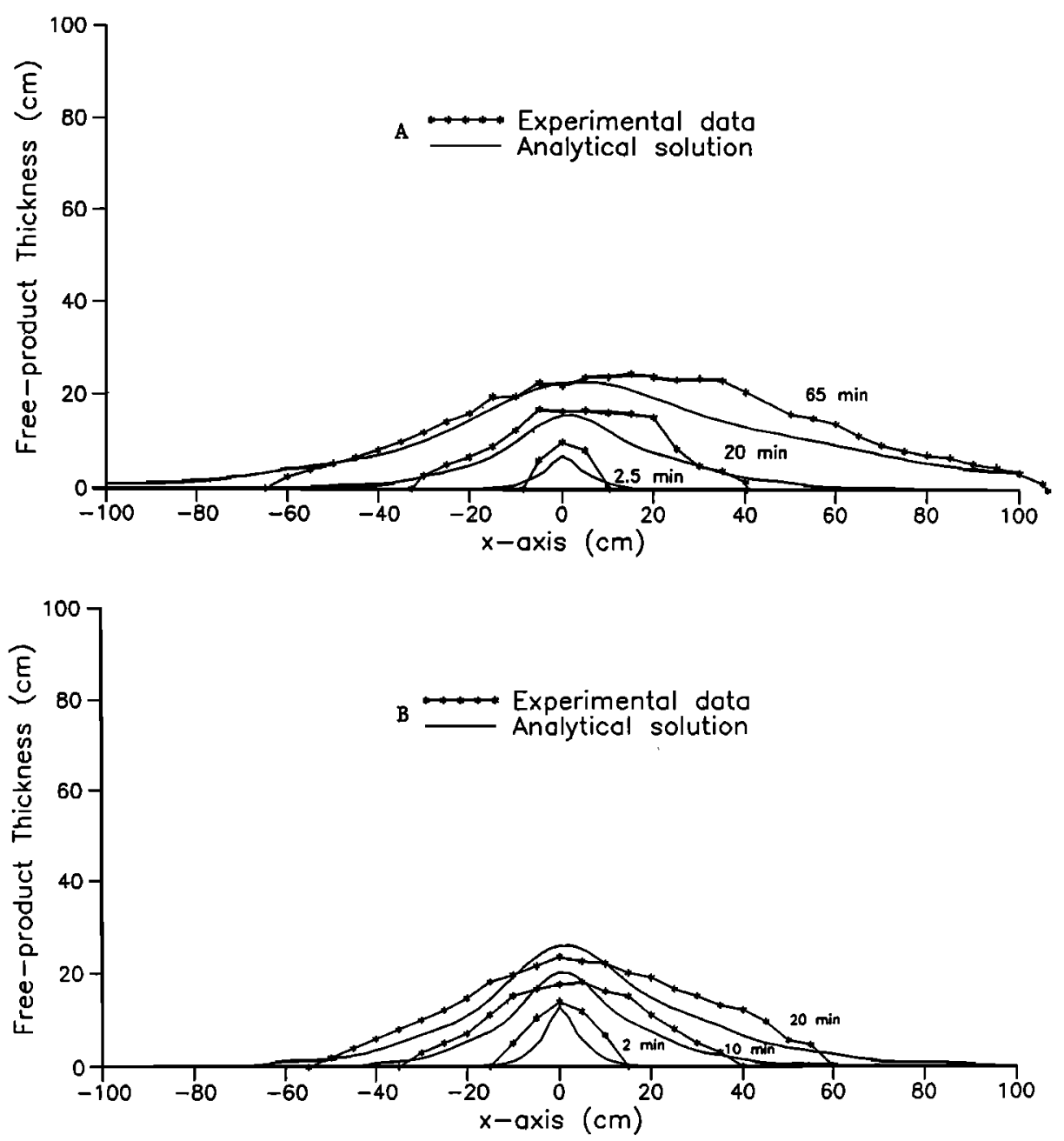

Figure 6. Comparison of simulated oil mound profiles (equation (20)) with experimental flume data for the oil leakage rates of (a) $10.61 \mathrm{~mL} \mathrm{~min} \mathrm{~mm}^{-1}$ and (b) $21.22 \mathrm{~mL} \mathrm{~min}^{-1} \mathrm{~cm}^{-1}$.

$6 \mathrm{~m}$, and the center coincides with the origin of the $x-y$ coordinate system. The material properties are the same as described in the previous case. The initial thickness of the oil $L_{\mathrm{i}}$ is $0.30 \mathrm{~m}$. The time step in the numerical solution is taken as 1 hour. Figure 4 illustrates $L=1 \mathrm{~cm}$ contours and oil mound profiles along $y=0$ at different times. After 3 days the $L=1$ $\mathrm{cm}$ contour moves significantly in the direction of ambient flow $\left(4 \mathrm{~m} \mathrm{~d}^{-1}\right)$ up to $37 \mathrm{~m}$ as measured from the initial center of the spill. For a similar problem, $L=1 \mathrm{~cm}$ contours and oil mound profiles of an initially circular oil mound are shown in Figure 5. The radius and initial thickness of the oil mound are $5 \mathrm{~m}$ and $0.3 \mathrm{~m}$, respectively. The behavior is similar to that of an initially rectangular oil because the volumes of oil in initially rectangular and circular mounds are quite close, i.e., $8.84 \mathrm{~m}^{3}$ for the rectangular mound and $8.27 \mathrm{~m}^{3}$ for the circular mound. Therefore the approximated initial geometry of the established mound is not very critical for estimating the extent of the spill with time.

\section{Experimental Studies}

We conducted laboratory experiments to test the validity of the model. All experiments were performed in a laboratory flume consisting of two glass walls and a steel frame. The flume was $244 \mathrm{~cm}$ long, $122 \mathrm{~cm}$ high, and $14.6 \mathrm{~cm}$ wide. At both ends of the flume, two perforated tubes connected to Cole Palmer Masterflex L/S pumps provide the hydraulic gradient for the flow field. Six-millimeter-ID glass tubes were used as piezometric tubes to measure the water table levels. The flume is filled with Vulcan \#1 filter sand. The porosity of sand is 0.39 , and the hydraulic conductivity of water is determined as 0.0008 $\mathrm{m} \mathrm{s}^{-1}$. Particle diameters fall within the range of $0.45-0.55$ $\mathrm{mm}$. The sand was placed into the flume under constant water mixing conditions to prevent any bubble entrapment and particle segregation. Soltrol-130, a Phillips 66 product, is used as the oil phase. Soltrol-130 is a combustible fluid with a mild odor, negligible solubility in water, and negligible volatility. Since Soltrol-130 is a colorless fluid, 0.9 grams of Oil Red O, an Aldrich Company product, are mixed with $1 \mathrm{~L}$ of Soltrol for visual observation. The density and dynamic viscosity of Soltrol 130 are given as $0.753 \mathrm{~g} \mathrm{~cm}^{-3}$ and $1.45 \mathrm{cp}$, respectively. Degrees of oil saturation within the oil, $S_{\mathrm{oo}}$, and in the unsaturated soil above the air-oil interface, $S_{\text {oun }}$, are determined as 0.9 and 0.1 , respectively.

The source was placed at a point just above the capillary fringe which was $8-9 \mathrm{~cm}$. A perforated $\mathrm{T}$ tubing was used as a distributed line source to inject Soltrol along the width of the 


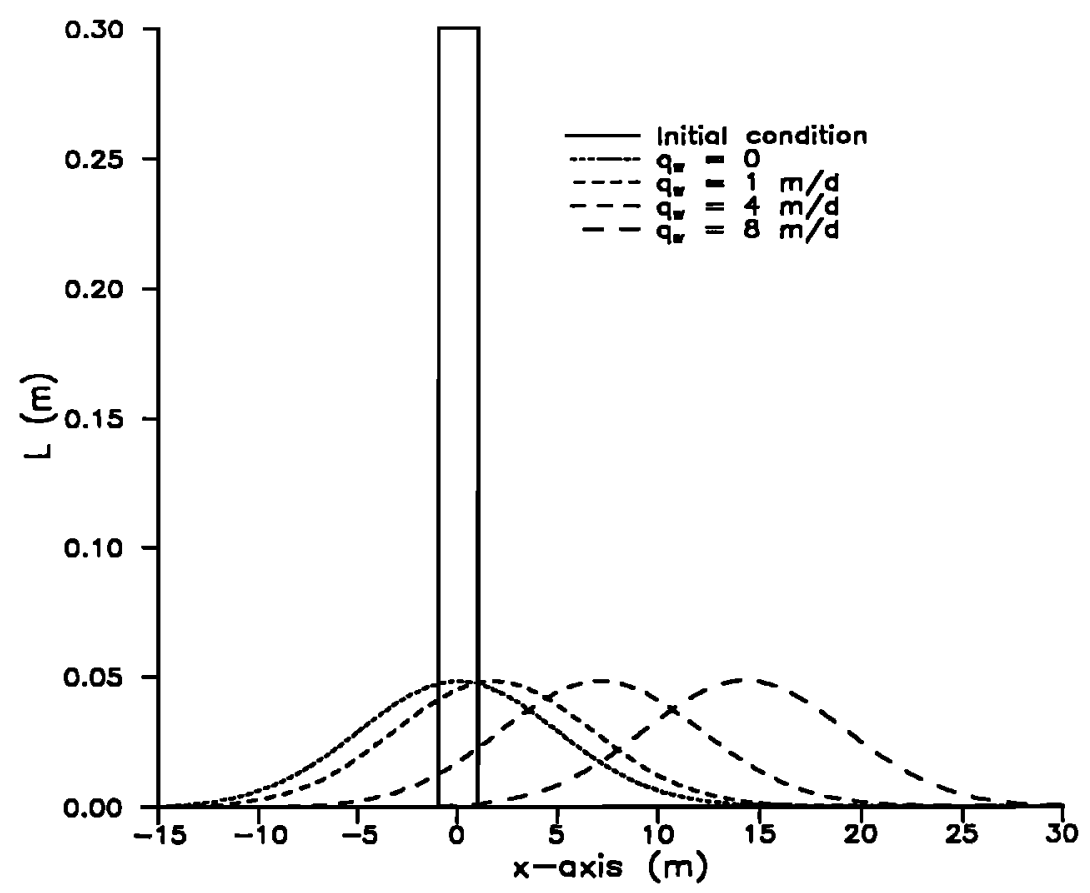

Figure 7. Sensitivity of the model to ambient groundwater flow rate at $t=1$ day.

flume. The horizontal ends of the $T$ tubing were sealed by silicone, and the tubing was connected to an oil pump to supply a constant rate oil leak. As oil was injected, the profile of the oil formation was visually observed, and air-oil and oil-water interfaces were recorded at selected intervals of time. The experiment was repeated at oil leakage rates of $10.61 \mathrm{~mL}$ $\mathrm{min}^{-1} \mathrm{~cm}^{-1}$ and $21.22 \mathrm{~mL} \mathrm{~min} \mathrm{~min}^{-1} \mathrm{~cm}^{-1}$. In both experiments the groundwater flow rate was $4 \mathrm{~m} \mathrm{~d}^{-1}$. A one-dimensional analytical solution of (9) is obtained by the Fourier transform to compare with experimental data,

$$
\begin{aligned}
& L(x, t)=\frac{1}{2 \pi} \int_{-\infty}^{+\infty}\left\{\left(\frac{2 L_{t}}{\lambda_{x}} \sin \left(\lambda_{x} b\right)-\frac{C \lambda_{x}^{2}}{\lambda_{x}^{4}+\lambda_{x}^{2} V^{2}}\right)\right. \\
& \cdot \cos \left[\lambda_{x}\left(x-\frac{V t}{R}\right)\right] \exp \left(-\frac{\lambda_{x}^{2}}{R} t\right) \\
& -\frac{C \lambda_{x} V}{\lambda_{x}^{4}+\lambda_{x}^{2} V^{2}} \sin \left[\lambda_{x}\left(x-\frac{V t}{R}\right)\right] \exp \left(-\frac{\lambda_{x}^{2}}{R} t\right) \\
& \left.+\frac{C \lambda_{x}^{2}}{\lambda_{x}^{4}+\lambda_{x}^{2} V^{2}} \cos \left(\lambda_{x} x\right)+\frac{C \lambda_{x} V}{\lambda_{x}^{4}+\lambda_{x}^{2} V^{2}} \sin \left(\lambda_{x} x\right)\right\} d \lambda_{x}
\end{aligned}
$$

Since there is no oil mound in the flume initially, $L_{\mathrm{i}}=0$. The linearization parameter $L_{\mathrm{o}}$ is calculated from $L_{\mathrm{o}}=Q_{\mathrm{o}} t /(A n)$ where $A$ is the experimentally determined area of the oil mound and $n$ is the porosity. As can be seen in Figure 6, the experimental and theoretical results are in good agreement for practical purposes. Some disagreement between the experimental and model results is observed at downstream profiles, especially at later times. This is due to the difficulty in determining the air-oil interface visually in the laboratory experiments. As the oil mound spreads on the water table, some ail mass moves upward by capillary forces, thus blurring the air-oil interface. Within the transitional region the oil saturation de- creases gradually with elevation. Therefore the experimentally obtained air-oil interface is an approximation subject to errors as high as a few centimeters, especially at the downstream profile. Hochmuth and Sunada [1985] reported the same difficulties in their flume experiments.

The one-dimensional analytical solution is used to study the effect of ambient groundwater velocity on the extent of spill migration. Migration of an oil mound initially $2 \mathrm{~m}$ long is analyzed for four different values of ambient groundwater velocity in Figure 7. Other parameters are kept constant. As expected, the groundwater velocity has a direct effect on oil mound migration. An interesting observation is made when the velocity is taken as $\mathbf{q}_{\mathrm{w}}=\mathbf{0}$ corresponding to a stagnant water table condition. In this case the initial oil mass collapses and spreads out under its own weight. With nonzero values of $\mathbf{q}_{\mathbf{w}}$ this profile has simply moved in the direction of ambient groundwater flow at the expected rate of $\left(\mathrm{q}_{\mathrm{w}} / K_{\mathrm{w}}\right)\left[K_{\mathrm{o}} / n\left(S_{\mathrm{oo}}-\right.\right.$ $\left.\left.S_{\text {oun }}\right)\right]$.

\section{Summary}

A model is presented to estimate the growth and spreading of an oil mound with ambient groundwater flow. The governing advective-dispersive transport equation obtained by depth averaging the oil mass balance equation is solved both analytically and numerically for two practical problems: formation and spreading of an oil mound on the water table and migration of an established oil mound with ambient groundwater flow. The numerical and analytical solutions show a reasonably close match. Although the model has some limitations, such as the absence of capillary pressure gradients, sharp saturation changes across the phase interfaces, and single mobile phase phase (i.e., oil flow only), the model results compare favorably with test data obtained by a laboratory flume experiment conducted to test the validity of the model. 
Acknowledgments. This study was partially funded through a summer employment of the first author (M.Y.C.) at HydroGeoLogic Inc., Herndon, Virginia. M.Y.C. appreciates the funding provided by P. Huyakorn. Constructive suggestions and comments of the reviewers are appreciated.

\section{References}

Abdul, S. A., S. F. Kia, and T. L. Gibson, Limitations of monitoring wells for the detection and quantification of petroleum products in soils and aquifers, Ground Water Monit. Rev., 9(2), 90-99, 1989.

Abriola, L. M., and H. W. Reeves, Slightly miscible organic chemical migration in porous media: Present and future directions in modeling, in Proceedings Environmental Research Conference on Groundwater Quality and Waste Disposal, edited by I. P. Murarka and S. Cordle, pp. 15.1-15.24, Electr. Power Res. Inst., Palo Alto, Calif., 1990.

Ahmed, A., A review of various expressions to estimate LNAPL thickness on groundwater, M. S. thesis, Dep. of Civil Eng., Tex. A\&M Univ., College Station, 1994.

Bear, J., Dynamics of Fluids in Porous Media, Elsevier, New York, 1972.

Corapcioglu, M. Y., R. Lingam, K. K. R. Kambham, and S. Panday, Multiphase contaminants in natural permeable media: Various modelling approaches, in Migration and Fate of Pollutants in Soils and Subsoils, edited by D. Petruzzelli and F. G. Helfferich, pp. 191-220, Springer-Verlag, New York, 1993.

Corapcioglu, M. Y., K. Tuncay, R. Lingam, and K. K. R. Kambham, Analytical expressions to estimate the free product recovery in oilcontaminated aquifers, Water Resour. Res., 30, 3301-3311, 1994.

Corapcioglu, M. Y., K. Tuncay, A. Ahmed, R. Lingam, K. K. R. Kambham, and B. K. Ceylan, Spreading and recovery of LNAPLs in oil contaminated aquiufers, in Recent Advances in Groundwater Pollution Control and Remediation, edited by M. Aral, pp. 275-306, Kluwer Acad., Norwell, Mass., 1996.

El-Kadi, A. I., Applicability of sharp interface models for NAPL transport, 2, Spreading of a LNAPL, Ground Water, 32, 784-793, 1994.

Greulich, R. H., Groundwater contamination from oil: Behavior, control and treatment, Water Supply, 15, 233-242, 1985.

Greulich, R., and H. Kaergaard, The movement of a continuously growing body of oil on the groundwater table, Nord. Hydrol., 15, 265-272, 1984.

Hantush, M. S., Growth and decay of groundwater-mounds in response to uniform percolation, Water Resour. Res., 3, 227-234, 1967.

Hantush, M. S., Unsteady movement of fresh water in thick unconfined saline aquifers, Bull. Int. Assoc. Sci. Hydrol, 13, 40-60, 1968.

Hochmuth, D. P., and D. K. Sunada, Ground water model of twophase immiscible flow in coarse material, Ground Water, 23, 617$626,1985$.

Holzer, T. L., Application of groundwater flow theory to a subsurface oil spill, Ground Water, 14, 138-145, 1976.

Host-Madsen, J., and K. H. Jensen, Laboratory and numerical investigations of immiscible multiphase flow in soil, J. Hydrol., 135, 13-52, 1992.

Huyakorn, P. S., Y. S. Wu, and N. S. Park, An improved sharpinterface model for assessing NAPL contamination and remediation of groundwater systems, J. Contam. Hydrol., 16, 203-234, 1994.
Kemblowski, M. W., and C. Y. Chiang, Hydrocarbon thickness fluctuations in monitoring wells, Ground Water, 28, 244-252, 1990.

Kessler, A., and H. Rubin, Relationships between water infiltration and oil spill migration in sandy soils, J. Hydrol., 91, 187-204, 1987.

Levy, B. S., P. J. Riordan, and R. P. Schreiber, Estimation of leak rates from underground storage tanks, Ground Water, 28, 378-384, 1990.

Lingam, R., and M. Y. Corapcioglu, Two-dimensional analytical solutions for a two-pump free product recovery system, Waste Manage., 15(5/6), 1995.

Mull, R., Migration of oil products in the subsoil with regard to groundwater pollution by oil, in Advances in Water Pollution Research, edited by S. H. Jenkins, pp. 1-8, Pergamon, Tarrytown, New York, 1971.

Mull, R., Calculations and experimental investigations of the migration of oil products on natural soils, paper presented at International Symposium on Groundwater Pollution by Oil Hydrocarbons, Int. Assoc. of Hydrogeol., Prague, June 5-9, 1978.

Reible, D. D., T. H. Illangasekare, D. V. Doshi, and M. E. Malhiet, Infiltration of immiscible contaminants in the unsaturated zone, Ground Water, 28, 685-692, 1990.

Schiegg, H. O., Methode zur abschatzung der ausbreitung von erdol derivaten in mit wasser und luft erfullten boden, Mitt. VAW 22, Versuchanst. für Wasserbau, Hydrol. und Glaziol., Eidgenöss. Tech. Hochsch. Zürich, Zürich, Switzerland, 1977.

Schiegg, H. O., Verdänguns-Simulation dreier nicht mischbarer fluide in poröser matrix, Mitt. VAW 40, Versuchsanst. für Wasserbau, Hydrologye und Glaziol., Eidgenöss. Tech. Hochsch. Zürich, Zürich, Switzerland, 1979.

Schiegg, H. O., and F. Schwille, Hydrocarbons in porous media, in Transport Processes in Porous Media, edited by J. Bear and M. Y. Corapcioglu, pp. 609-702, Kluwer Acad., Norwell, Mass., 1991.

Schwille, F., Groundwater pollution in porous media by fluids immiscible with water, Sci. Total Environ., 21, 173-185, 1981.

Schwille, F., Migration of organic fluids immiscible with water in the unsaturated zone, in Pollutants in the Unsaturated Zone, edited by B. Yaron, G. Dagan, and J. Goldschmid, pp. 27-36, Springer-Verlag, New York, 1984.

van Dam, J., The migration of hydrocarbons in a water-bearing stratum, in Joint Problems of the Oil and Water Industries, edited by P. Hepple, pp. 55-96, Inst. of Pet., London, 1967.

Verruijt, A., Elastic storage of aquifers, in Flow Through Porous Media, edited by R. J. M. DeWiest, pp. 331-376, Academic, San Diego, Calif., 1969

Weaver, J. W., R. J. Charbeneau, and B. K. Lien, A screening model for nonaqueous phase liquid transport in the vadose zone using Green-Ampt and kinetic wave theory, Water Resour. Res., 30, 93105,1994

B. R. Ceylan and M. Y. Corapcioglu, Department of Civil Engineering, Texas A\&M University, College Station, TX 77843-3136. (e-mail: yavuz@acs.tamu.edu)

K. Tuncay, Izmir Institute of Technology, Anafartalar Cad. 904, Basmane 35230, Izmir, Turkey.

(Received October 16, 1995; revised December 4, 1995; accepted December 18, 1995.) 